\title{
Globalização: Novo paradigma das ciências sociais
}

\section{OCTAVIO IANNI}

$\mathrm{N}$ esta altura da história, no declínio do século XX e limiar do $\mathrm{XXI}$, as ciências sociais se defrontam com um desafio episte-

mológico novo. O seu objeto transforma-se de modo visível, em amplas proporçóes e, sob certos aspectos, espetacularmente. Pela primeira vez, são desafiadas a pensar o mundo como uma sociedade global. As relaçóes, os processos e as estruturas económicas, políticas, demograficas, geográficas, históricas, culturais e sociais, que se desenvolvem em escala mundial, adquirem preeminência sobre as relaçóes, processos e estruturas que se desenvolvem em escala nacional, $O$ pensamento científico, em suas produçóes mais notáveis, elaborado primordialmente com base na reflexão sobre a sociedade nacional, não é suficiente para apreender a constituiçáo e os movimentos da sociedade global.

O paradigma clássico das ciências sociais foi constituído e continua a desenvolver-se com base na reflexáo sobre as formas e os movimentos da sociedade nacional. Mas a sociedade nacional está sendo recoberta, assimilada ou subsumida pela sociedade global, uma realidade que não está ainda suficientemente reconhecida e codificada. A sociedade global apresenta desafios empíricos e metodológicos, ou históricos e teb́ricos, que exigem novos conceitos, outras categorias, diferentes interpretações. "Sempre houve um enorme debate sobre como a sociedade e o estado relacionam-se, qual deveria subordinar o outro e qual encarnar os valores morais mais elevados. Assim, ficamos acostumados a pensar que as fronteiras da sociedade e do estado são as mesmas ou, se não, poderiam (e deveriam) ser. (...) Vivemos em estados. Há uma sociedade sob cada estado. Os estados têm história e portanto tradiçóes. (...) Esta imagem da realidade social não era uma fantasia, tanto assim que teóricos colocados em perspectivas ideograficas e nomotéticas desempenhavam-se com razó́vel desenvoltura, utilizando esses enfoques acerca da sociedade e estado e alcançando alguns resultados plausíveis. $O$ único problema era que, à medida que o tempo corria, mais e mais anomations revelavam-se inexplicadas nesse esquema de referência; e mais e mais lacunas (de zonas da atividade humana não pesquisadas) pareciam emergirn (1). 
Ocorre que a sociedade global não $t$ a mera extensáo quantitativa e qualitativa da sociedade nacional. Ainda que esta continue a ser básica, evidente $\mathrm{e}$ indispensável, manifestando-se inclusive em âmbito internacional, é inegável que a sociedade global se constitui como uma realidade original, desconhecida, carente de interpretações.

A sociedade global já tem sido objeto de estudos e interpretaçŏes, em seus aspectos históricos, políticos, econômicos, culturais, geográficos, demográficos, geopolíticos, ecológicos, religiosos, lingüísticos, artísticos e filosóficos. Além das indicaçôes e intuiçōes que freqüentemente aparecem nos estudos sobre a sociedade nacional, multiplicam-se as reflexóes sobre as configuraçóes e os movimentos da sociedade global. Já são muitos os que pensam a sociedade em âmbito transnacional, mundial ou propriamente global, mesmo quando não estáo utilizando esta noçáo, mesmo quando continuam a pensar a nação. Em forma sintética, pode-se dizer que essa problemática está presente nos estudos e interpretaçōes sobre relaçōes internacionais, geopolítica, inregraçăo regional, sistema-mundo, economia-mundo, três mundos, quatro mundos, guerra fria, fim da guerra fria, fim da história, nova divisão internacional do trabalho, fábrica global, cidade global, aldeia global, shopping center global, disneylândia global, planeta terra, norte e sul, ONU, Unesco, Unicef, FAO, FMI, BIRD, GATT, OTAN, NAFTA, Mercosul, Casa da Europa, Estados Unidos da Europa, espaço europeu, espaço do Pacífico, imperialismo, pós-imperialismo, dependência, nova dependência, interdependência, multilateralismo, multinacional, transnacional, ascensão e queda das grandes potências, Ocidente e Oriente, ciclo Kondratieff; telecomunicaçóes, mídia mundial, indústria cultural, cultura internacional popular, marketing global, globalização e fragmentaçáo, novo mapa do mundo, modernidade-mundo, pós-modernidade.

Este é um momento epistemológico fundamental: o paradigma clássico, fundado na reflexăo sobre a sociedade nacional, está sendo subsumido formal e realmente pelo novo paradigma, fundado na reflexáo sobre a sociedade global. O conhecimento acumulado sobre a sociedade nacional não é suficiente para esclarecer as configuraçóes e os movimentos de uma realidade que já é sempre internacional, multinacional, transnacional, mundial ou propriamente global. É óbvio que a sociedade nacional continua a ter vigência, com seu território, população, mercado, moeda, hino, bandeira, governo, constituiçáo, cultura, religiáo, história, formas de organização social e técnica do trabalho, façanhas, heróis, santos, monumentos, ruínas. Ela constitui o cenário no qual os seus membros movimentam-se, vivem, trabalham, lutam, pensam, fabulam, morrem. Tanto assim que subsistem e ressurgem nacionalismos, provincianismos, regionalismos, etnicismos, fundamentalismos e identidades 
em muitos lugares, nos diversos quadrantes do mundo. Mas a sociedade nacional não dá conta, nem empírica nem metodologicamente ou histórica e teoricamente, de toda a realidade na qual se inserem indivíduos e classes, naçóes e nacionalidades, culturas e civilizaçōes. Aos poucos, e às vezes de repente, a sociedade global subsume formal ou realmente a sociedade nacional, compreendendo indivíduo, grupo, classe, movimento social, cultura, língua, religião, moeda, mercado, formas de trabalho, modos de vida. Tudo iśto continua vigente, como nacional, com toda a sua força original. Mas tudo isto, simultaneamente, articula-se dinâmica e contraditoriamente com as configuraçóes e os movimentos de sociedade global. Como totalidade geográfica e histórica, espácio-temporal, em suas dimensōes sincrônicas e diacrônicas, a sociedade global se constitui como um momento epistemológico fundamental, novo, pouco conhecido, desafiando a reflexão e a imaginação de cientistas sociais, filósofos e artistas.

Os estudos e as interpretaçōes da sociedade global apresentam algumas características que merecem ser registradas. Cada uma de per si, e todas em conjunto, permitem visualizar um pouco melhor tanto a originalidade do novo objeto das ciências sociais como as dificuldades epistemológicas que suscita.

Primeiro, baseiam-se principalmente nos ensinamentos das seguintes teorias, muito correntes nas ciências sociais: evolucionismo, funcionalismo, sistêmica, estruturalista, weberiana e marxista. Essas sáo as que predominam, às vezes em termos bastante sistemáticos, outras vezes utilizadas de modo fragmentário. Também há tentativas de combinar elementos de várias teorias, em formulaçóes ecléticas. Em várias casos, no entanto, fica evidente a dificuldade que alguns autores enfrentam para libertar-se dos quadros de referência representados pela sociedade nacional, como emblema do paradigma clássico, e pensar a sociedade global em toda a sua originalidade.

Segundo, priorizam determinados aspectos da sociedade global: econômicos, financeiros, tecnológicos, informáticos, culturais, religiosos, políticos, geopolíticos, ecológicos, sociais, históricos, geográficos e outros. Sáo poucos os que formulam abordagens gerais, abrangentes, integrativas. Também são poucos os que reconhecem que o conjunto das relaçóes, processos e estruturas que descrevem e interpretam diz respeito a um objeto novo constituído pela sociedade global.

Terceiro, a maioria situa-se em perspectiva que se pode denominar de convencional. Focaliza este ou aquele aspecto da sociedade global, priorizando antecipadamente uma perspectiva: a superpotência mundial; uma ou várias das naçóes dominantes ou centrais no cenário mun- 
dial; uma ou várias naçóes do ex-Terceiro Mundo, do sul ou da periferia, tais como as asiáticas, africanas, latino-americanas e inclusive remanescentes do ex-bloco soviético do leste europeu; a comunidade européia; a classe ou as classes dominantes; as classes subalternas, compreendendo trabalhadores assalariados em geral, proletariado e campesinato; as etnias minoritárias; a luta pela soberania nacional, com base em projeto capitalista, socialista ou terceira pia ; a rede intra e intercorporaçóes, conglomerados ou empresas, compreendendo muitas vezes alianças estratégicas entre elas; a nova divisão internacional do trabalho e da produção; a mídia internacional; um ou outro fundamentalismo religioso, incluindo-se o islamismo, catolicismo, protestantismo e outros; a luta pela hegemonia mundial por parte desta ou daquela nação.

Quarto, o método comparativo evidentemente está na base de praticamente todos os estudos e interpretaçóes. Comparam-se naçóes e continentes, tecnologias e mercadorias, regimes políticos e políticas governamentais, indicadores econômicos, financeiros, políticos, sociais e culturais, economias estatizadas mistas e de empresa privada, mercado e planejamento. Há casos em que a comparação elege relaçóes, processos e estruturas, procurando combinar configuraçóes sincrônicas e diacrônicas. Em outros casos, comparam-se índices, indicadores, variáveis. É claro que o recurso ao método comparativo apóia-se, em última instância, em uma das teorias mobilizadas para a pesquisa: evolucionismo, funcionalismo, sistêmica, estruturalista, weberiana ou marxista. Em geral, a comparação toma como referência aberta ou implícita este ou aquele país moderno, desenvolvido, industrializado, pós-industrial.

Quinto, são poucos, muito poucos, os que se posicionam nos horizontes da desterritorializaçáo, uma perspectiva que pode passar pelas convencionais, mas não se fixa em nenhuma, como a que seria prioritária, privilegiada ou mais avanfada. Dado ao fato de que esse novo objeto das ciências sociais não só é novo mas também muito problemático, seria apressado estabelecer precipitadamente uma perspectiva como prioritária ou exclusiva. A fecundidade possível da reflexăo sobre a sociedade global, em suas configuraçóes e seus movimentos, pode ampliarse bastante se o sujeito do conhecimento não permanece no mesmo lugar, deixando que o seu olhar flutue livre e atento por muitos lugares, próximos e remotos, presentes e pretéritos, reais e imaginários.

Sim, a sociedade global é o novo objeto das ciências sociais. Ao lado da sociedade nacional, vista como um todo e também em suas partes, as ciências sociais começam a debruçar-se sobre a sociedade global, vista como um todo e também em suas partes. São dois objetos presentes: um dos quais bastante conhecido, codificado, interpretado, 
ao passo que o outro ainda por se conhecer, se explicar. A sociedade nacional pode ser vista como o emblema do paradigma clássico das ciências sociais, com o qual elas nascem, amadurecem e continuam a se desenvolver. Enquanto que a sociedade global pode ser vista como o emblema de um paradigma emergente. Envolve um novo paradigma, tanto porque a sociedade global encontra-se em constituiçáo, em seus primórdios, como porque carece de conceitos, categorias, interpretaçóes.

Acontece que a globalização em curso no fim do século XX pode ser algo muito novo, a despeito da impressáo de que parece apenas continuidade. A humanidade de que se falava no passado era uma idéia, hipótese, utopia. A globalizaçăo que prenuncia o século XXI está aí, dada, evidente, esperando ser pensada, revelando a humanidade como ela começa a ser. "A idéia de humanidade é um pensamento antigo e persistente. Mas foi como uma idéia potencialmente realizável, ou como um ideal a ser procurado, que empolgou a atençáo de filósofos. No entanto, à medida em que se expande a sociedade ocidental, desde o século XVI, acentua-se a distância entre a realidade e o ideal. A diversidade cultural e o freqüiente desentendimento mútuo parecem caracterizar o mundo real. $O$ método comparativo tornou-se central na sociologia precisamente como resposta a essa experiência. Foi a realidade do desenvolvimento social que mudou essa situaçáo. Desde a Segunda Guerra Mundial, tem havido um crescente reconhecimento, entre sociologos, de que a populaçáo mundial está envolvida em um único sistema social mundial. Sociedade, como tal, passa a compreender uma multidão de sociedades que, no contexto de um sistema mais amplo, podem somente encontrar uma autonomia relativa e condicionada, em grande medida como naçóos-estados estreitamente entrelaçados (2).

Revertem-se perspectivas e possibilidades de ser de uns e outros, em todo o mundo. O local e o global determinam-se reciprocamente, umas vezes de modo congruente e conseqüente, outras de modo desigual e desencontrado. Mesclam-se e tencionam-se singularidades, particularidades e universalidades. "A globalizaçăo pode assim ser definida como a intensificação das relaçóes sociais em escala mundial, que ligam localidades distantes de tal maneira que acontecimentos locais são modelados por eventos ocorrendo a muitas milhas de distância e vice-versa. Este é um processo dialético porque tais acontecimentos locais podem se deslocar numa direçáo inversa às relaçóes muito distanciadas que os modelam. A transformagáo local é tanto uma parte da globalizaçăo quanto a extensão lateral das conexóes sociais através do tempo e espaço. Assim, quem quer que estude as cidades hoje em dia, em qualquer parte do mundo, está ciente de que o que ocorre numa vizinhança local tende 
a ser influenciado por fatores - tais como dinheiro mundial e mercados de bens - operando a uma distância indefinida da vizinhança em questăo" (3).

Esse o contexto em que todas as ciências sociais são postas diante de novo desafio epistemológico. Muitos dos seus conceitos, categorias e interpretações são postos em causa. Alguns tornam-se obsoletos, outros perdem parte de sua vigência e há os que são recriados. Mas logo se coloca o desafio de criar novos. À medida em que a realidade social passa por uma verdadeira revoluçáo, quando o objeto das ciências sociais se transfigura, nesse contexto descortinam-se outros horizontes para 0 pensamento.

Há noçóes que sofrem uma espécie de obsolescência, em certos casos parcial, em outros total. $O$ estado-nação, por exemplo, entra em declínio, como realidade e conceito. Náo se trata de dizer que deixará de existir, mas que está realmente em declínio, passa por uma fase crítica, busca reformular-se. As forças sociais, econômicas, políticas, culturais, geopolíticas, religiosas e outras, que operam em escala mundial, desafiam o estado-nação, com a sua soberania, como o lugar da hegemonia. Sendo assim, os espaços do projeto nacional, seja qual for a sua tonalidade política ou econômica, reduzem-se, anulam-se ou somente podem ser recriados sob outras condiçóes. A globalizaçáo cria injunçōes e estabelece parâmetros, anula e abre horizontes. Mas o pensamento científico parece um tanto tímido, surpreso ou mesmo atônito, diante das implicaçōes epistemológicas da globalização.

As noçóes de interdependência, dependência e imperialismo também estão postas em causa, se admitimos que o estado-naçáo está em crise, enfrenta uma fase de declínio, busca reformular-se. As grandes e pequenas naçóes, centrais e periféricas, dominantes e subordinadas, ocidentais e orientais, ao sul e ao norte, todas se deparam com o dilema da reformulação das condições de soberania e hegemonia. É claro que há blocos, geopolíticas, imperialismos, dependências e interdependências nesse mesmo cenário. Há vínculos antigos e novos que atrelam nações umas às outras, não só em condiçóes de igualdade mas principalmente de desigualdades. Também as organizaçốes internacionais, compreendendo a ONU, FMI, BIRD, GATT e outras exercem as suas atividades priorizando interesses de naçóes com maior poder econômico, político, militar, cultural. Essa continua a ser uma dimensão importante do cenário mundial. Simultaneamente, no entanto, declinam e reformulam-se as condiçóes de soberania e hegemonia, em todos os quadrantes. Mesmo porque já há centros de poder, em escala global, que sobrepassam soberanias e hegemonias. As empresas, corporaçóes e conglomerados trans- 
nacionais, em suas redes e alianças, em seus planejamentos sofisticados, operando em escala regional, continental e global, dispóem de condiçóes para impor-se aos diferentes regimes políticos, às diversas estruturas estatais, aos distintos projetos nacionais.

Este o horizonte, das naçóes e metáforas que as ciências sociais estáo sendo desafiadas a criar: aldeia global, fábrica global, cidade global, nave espacial, desterritorializaçăo, re-territorialização, redes inter e intracorporaçóes, alianças estratégicas de corporaçốes, nova divisão internacional do trabalho, neofordismo, acumulação flexível, zona franca, mercado global, mercadoria global, moeda global, planejamento global, tecnocosmo, planeta terra, sociedade civil mundial, cidadania mundial, contrato social universal.

Náo é suficiente transferir conceitos, categorias e interpretaçōes elaborados sobre a sociedade nacional para a global. Quando se trata de movimentos, relaçóes, processos e estruturas característicos da sociedade global, náo basta utilizar ou adaptar o que se sabe sobre a sociedade. nacional. As noçōes de sociedade, estado, nação, partido, sindicato, movimento social, identidade, território, regiáo, tradiçáo, história, cultura, soberania, hegemonia, urbanização, industrializaçăo, arcaico, moderno e outras náo se transferem nem se adaptam facilmente. As relaçóes, processos e estruturas de dominaçáo e apropriaçáo, integraçáo e antagonismo característicos da sociedade global exigem também novos conceitos, categorias, interpretaçóes.

Logo fica evidente que não se trata de dois objetos distintos, com tessituras e dinâmicas próprias, alheias. Implicam-se reciprocamente, em articulaçóes sincrônicas e diacrônicas diversas, desde convergentes e antagônicas. Envolvem possibilidades diferentes no que se refere às formas do espaço, às duraçôes do tempo. São duas totalidades bastante articuladas, cada uma a seu modo, mas reciprocamente referidas, sendo que a global tende a subsumir formal ou realmente a nacional.

É claro, há autores que reconhecem que as ciências sociais se encontram em face de modificaçóes radicais em seu objeto. Reconhecem que a globalizaçáo implica desafios empíricos, metodológicos, teóricos e, propriamente, epistemológicos. Mas agarram-se a conceitos, categorias e interpretaçóes acumulados com base na reflexáo sobre os problemas da sociedade nacional, do estado-naçáo. Procuram transferir ou reformular esse patrimônio, induzindo a idéia de que a sociedade global significa uma ampliação da nacional, quando năo simplesmente uma soma de nacionais. Inclusive há aqueles que tomam as sociedades mais deserevolvidas, dominantes ou hegemônicas como parâmetro do que pode ser o mundo. Nestes casos, a globalizaçáo tende a ser vista como euro- 
peizaçáo, americanizaçăo ou ocidentalização, ainda que se fale em modernização, secularizaçăo, individuaçăo, urbanizaçăo, industrialização ou modernidade (4).

Ocorre que a problemática da globalizaçáo se encontra ainda em processo de equacionamento empírico, metodológico e teórico. Mais que isso, apenas começa a ser percebida em suas implicaçóes epistemológicas. Trata-se de uma realidade que pode ser vista como uma totalidade em formaçáo. Constitui-se como um jogo de relações, processos e estruturas de dominação e apropriação, integraçăo e contradiçăo, soberania e hegemonia, configurando uma totalidade em movimento, complexa e problemática. Trata-se de um universo múltiplo, uma sociedade desigual e contraditória, envolvendo economia, política, geografia, história, cultura, religião, língua, tradição, identidade, etnicismo, fundamentalismo, ideologia, utopia. Nesse horizonte, multiplicam-se as possibilidades e as formas do espaço e tempo, o contraponto parte e todo, a dialética singular e universal.

São ainda poucas as indicaçóes, intuiçōes e interpretaçóes de que a sociedade global corresponde a uma nova realidade, uma totalidade abrangente, subsumindo formal ou realmente as nacionais. "A idéia central é a de que existe um sistema global com vida própria, independentemente das sociedades nacionais constituídas que existem dentro das suas fronteiras. (...) Embora os estudos sobre o moderno sistema mundial envolvam grandes divergências quanto a objeto, horizontes temporais e metodologias, todos estão de acordo quanto a duas questóes: primeiro, reconhecem que um sistema mundial ou global existe além das sociedades nacionais, que podem ser estudadas de per si. Reconhecem que a economia mundial, ou o estado do sistema internacional, possuem vida e dinâmica estrutural próprias, podendo ser identificados $e$ interpretados. Segundo, este sistema-mundo exerce influência sobre o desenvolvimento e, mais importante ainda, o subdesenvolvimento das sociedades nacionais inseridas nas estruturas globais. Não há apenas um sistema-mundo lá, ele também determina o desenvolvimento de áreas dentro das suas fronteiras. Com efeito, o desenvolvimento ou subdesenvolvimento de um país tem mais a ver com a sua localização hierárquica na divisáo do trabalho mundial do que com a própria taxa de desenvolvimento interno. (...) Denominamos esta ciência emergente da dinâmica global como globologia, o que simplesmente significa a ciência de distintos processos globais, sejam econômicos, políticos ou culturais. Se a sociologia é a ciência dos sistemas sociais, então globologia é a ciência do sistema global. Globologia, pois, é análoga à sociologia e refere-se aos estudos de estruturas e processos do sistema-mundo como um todo, da mesma forma que a sociologia se refere ao estudo de estruturas e processos sociais" (5). 
Há autores, no entanto, que sistematizam de modo mais ou menos consistente e convincente suas idéias sobre a sociedade global, como um todo ou em algumas das suas partes. Ultrapassam o nível das indicaçóes ou intuiçóes preliminares. Focalizam diretamente a problemática da globalização, colaborando no sentido de equacionar essa problemática em suas implicações empíricas, metodológicas, teóricas e, em certos casos, também epistemológicas. "Globalizaçáo diz respeito a todos os processos por meio dos quais os povos do mundo são incorporados em uma única sociedade mundial, a sociedade global. Globalismo é uma das forças que atuam no desenvolvimento da globalização" (6).

A reflexão sobre a sociedade global, em suas configuraçóes e movimentos, transborda os limites convencionais desta ou daquela ciência social. Ainda que haja ênfases e prioridades, quanto a este ou aquele aspecto da globalização, logo fica evidente que qualquer análise envolve necessariamente várias ciências. A economia da sociedade global envolve também aspectos políticos, históricos, geográficos, demográficos, culturais e outros. A cultura da globalização passa pela cultura de massa, indústria cultural, mídia impressa e eletrônica, religióes e línguas, além de outros aspectos que transbordam limites convencionais da antropologia e da sociologia. Năo sempre, mas em muitos casos, os estudos e as interpretaçōes sobre globalização reabrem questōes epistemológicas que pareciam resolvidas, quando as ciências sociais trabalhavam principalmente com a sociedade nacional, como emblema do paradigma clássico. "A questão diante de nós, hoje, é se há algum critério que possa ser usado para assegurar, com relativa clareza e consistência, as fronteiras entre as quatro presumidas disciplinas de antropologia, economia, ciência política e sociologia. A análise dos sistemas-mundo responde com inequívoco näo a esta pergunta. Todos os critérios presumíveis - níveis de análise, objetos, métodos, enfoques teóricos - ou não são mais verdadeiros na prática, ou, se mantidos, sáo obstáculos a conhecimentos posteriores, antes do que estímulos para a sua criação" (7).

As noçóes de espaço e tempo, fundamentais para todas as ciências sociais, estão sendo revolucionadas pelos desenvolvimentos científicos e tecnológicos incorporados e dinamizados pelos movimentos da sociedade global. As realidades e os imaginários lançam-se em outros horizontes, mais amplos que a província e a naçáa, a ilha e o arquipélago, a regiáo e o continente, o mar e o oceano. As redes de articulaçóes e as alianças estratégicas de empresas, corporaçóes, conglomerados, fundaçóes, centros e institutos de pesquisas, universidades, igrejas, partidos, sindicatos, governos, meios de comunicação impressa e eletrônica, tudo isso constitui e desenvolve tecidos que agilizam relaçóes, processos e estruturas, espaços e tempos, geografias e histórias. O local e o global 
estão distantes e próximos, diversos e mesmos. As identidades embaralham-se e multiplicam-se. As articulaçóes e as velocidades desterritorializam-se e re-territorializam-se em outros espaços, com outros significados. O mundo se torna mais complexo e mais simples, micro e macro, épico e dramático. "Há, hoje, um relógio mundial, fruto do progresso técnico, mas o tempo-mundo é abstrato, exceto como relaçáo. Temos, sem dúvida, um tempo universal, tempo despótico, instrumento de medida hegemônico, que comanda o tempo dos outros. Esse tempo despótico é responsável por temporalidades hierárquicas, conflitantes, mas convergentes. Nesse sentido todos os tempos são globais, mas não há um tempo mundial. O espaço se globaliza, mas não é mundial como um todo, senão como metáfora. Todos os lugares são mundiais, mas não há um espaço mundial. Quem se globaliza, mesmo, são as pessoas e os lugares" (8).

A rigor, a reflexão sobre a sociedade global reabre questóes epistemológicas fundamentais: espaço e tempo, sincronia e diacronia, micro e macro, singular e universal, individualismo e holismo, pequeno relato e grande relato. Sáo questóes que se colocam a partir do reconhecimento da sociedade global como uma totalidade complexa e problemática, articulada e fragmentada, integrada e contraditória. Simultaneamente às forças que operam no sentido da articulação, integraçáo e até mesmo homogeneização, operam forças que afirmam e desenvolvem não só as diversidades, singularidades ou identidades, mas também hierarquias, desigualdades, tensóes, antagonismos. São forças que alimentam tendências integrativas e fragmentárias, compreendendo nação e nacionalidade, grupo e classes sociais, provincianismo e regionalismo, localismo e cosmopolitismo, capitalismo e socialismo.

É óbvio que a globalização envolve o problema da diversidade. Praticamente todos os estudos e interpretaçóes sobre a sociedade global colocam esse problema. A reflexão sobre a diversidade não pode estar ausente, já que implica aspectos empíricos, metodológicos, teóricos e propriamente epistemológicos. Logo que se reconhece que a sociedade global é uma realidade em processo, que a globalizaçáo atinge as coisas, as gentes $\mathrm{e}$ as idéias, bem como as sociedades $\mathrm{e}$ as naçóes, as culturas $\mathrm{e}$ as civilizaçóes, desde esse momento está posto o problema do contraponto globalização e diversidade, assim como diversidade e desigualdade, ou integraçáo e antagonismo.

Mas ocorrem posicionamentos exacerbados. Alguns chegam ao extremo de autonomizar o diferente, diverso, sui generis. Apegam-se ao local e esquecem o global, imaginando que o singular prescinde do universal. Enfatizam a diferença, tornando-a original, estranha, exótica; ou 
elegendo-a primordial, isenta, ideal. Incorrem no etnocentrismo ocidentalizante que pretendem criticar, tomando o outro, que querem resgatar e proteger, em um ente abstrato, deslocado da realidade, da trama que o constitui como diferente. Alimentam uma nostálgica utopia escondida no próprio imaginário. Outros, subordinam toda diversidade à globalidade. Reconhecem a diversidade, mas não a contemplam, não percebem a sua originalidade. Esquecem que o local pode não só se afirmar como se recriar no contraponto com o global. Naturalmente entre esses dois extremos, uns priorizando o local e outros o global, há toda uma gama de posições. Revelam-se nas reflexões sobre os mais diversos aspectos da realidade.

Esse o contexto metodológico em que se situam algumas das controvérsias correntes nas ciências sociais. Uns preocupam-se com a diversidade, procurando a identidade, e protestando contra a globalidade. Outros contrapóem o saber local ao global, falando em indigenizafẫo ou criolizafáno das ciências sociais, fazendo reservas ou oposiçáo à ocidentalizagáo. Há uma "crescente demanda pela indigenização das ciências sociais no Oriente Médio e no Sudoeste Asiático, em substituição à ocidentalização e importação das ciências sociais distorcidas. Recentemente deflagrou-se um clamor pela pureza dos traços culturais. Aqueles, no entanto, que pedem autenticidade pela indigenizafäo podem não estar ainda cientes de que o saber local, sobre o qual querem construir uma alternativa, há muito tempo tem sido parte das estruturas globais; ou de que desempenham uma parte do jogo da cultura global, que também pede a essencia da verdade local" (9).

Neste ponto, cabe relembrar que o problema da diversidade está sempre presente nas configuraçóes e movimentos da sociedade global. Seria impossível imaginar a globalização sem a multiplicidade dos indivíduos, grupos, classes, tribos, naçóes, nacionalidades, culturas etc. São estes que se globalizam, ao acaso ou por indução, sabendo ou não. $\mathrm{Da}$ mesmo forma que são estes que vivem, agem, pensam, aderem, protestam, mudam, transformam-se. "O capitalismo global simultaneamente promove e é condicionado pela homogeneidade cultura e pela heterogeneidade cultural. A produção e consolidação da diferença e variedade é um ingrediente essencial do capitalismo contemporâneo, que $\hat{\epsilon}, \mathrm{em}$ todos os casos, crescentemente envolvido na múltipla variedade de micromercados (nacional, cultural, racial e étnico, de gênero, socialmente estratificado e assim por diante). Ao mesmo tempo, o micromercado ocorre no contexto das crescentes práticas econômicas universais-globais" (10).

Em bom entendimento, não se trata de priorizar um ou outro momento da realidade e da reflexão. É claro que a análise da sociedade 
global envolve sempre tribo, nação e nacionalidade, história e geografia, cultura e civilizaçáo, indivíduo, grupo e classe, sindicato, partido político, movimento social e corrente de opiniáo pública, indústria e agricultura, mercado e planejamento, campo e cidade, identidade, diversidade, desigualdade e contradiçăo, soberania e hegemonia, reforma e revolução, paz e guerra.

Em todos os casos está em causa o contraponto local e global, parte e todo, micro e macro, individualismo e holismo. Em todos os casos, os momentos lógicos da reflexáo científica necessariamente envolvem a dialética singular e universal. Não se trata de priorizar um momento, em detrimento do outro, mas reconhecer que ambos se constituem reciprocamente, articulados harmônica, tensa e contraditoriamente, envolvendo múltiplas mediaçóes. São mediaçōes indispensáveis e secundárias, evidentes e insuspeitadas, próximas e remotas. Podem ser signos com sinais trocados, reversos, recriados.

Nesses termos é que é indispensável que toda reflexăo sobre a sociedade global contemple tanto a diversidade como a globalidade, reconhecendo que ambas se constituem simultânea e reciprocamente. Quando isso não ocorre, a reflexão se arrisca a permanecer na mera descriçáo, ideologizar este ou aquele momento da análise, ou ficar a meio caminho da interpretaçáo. E difícil, na verdade impossível, que o conceito, a categoria ou a interpretaçáo deixem de contemplar o contraponto singular e universal (11).

No conjunto, os estudos e as interpretaçóes sobre a sociedade global, em suas configuraçóes e em seus movimentos, permitem algumas observaçóes do maior interesse para o esclarecimento desse novo objeto das ciências sociais.

Primeiro, a sociedade global se constitui desde o início como uma totalidade problemática, complexa e contraditória, aberta em movimento. Está impregnada e atravessada por totalidades também notáveis, às vezes também decisivas, ainda que subsumidas formal ou realmente pela totalidade mais ampla, abrangente, global: estado-naçáo, bloco geopolítico, sistema econômico regional, grande potência, empresa transnacional, ONU, FMI, Banco Mundial, indústria cultural e outras; também tribo, nação, nacionalidade, etnia, religiáo, língua, cultura e outras realidades tambem fundamentais. As próprias formas de pensamento inserem-se na dinâmica da sociedade global, no seu todo ou em suas partes, operando no sentido da constituiçáo de todos os subordinados, ou da constituiçáo da sociedade global como uma totalidade abrangente, sempre problemática, complexa e contraditória. 
Segundo, a sociedade global é o cenário mais amplo do desenvolvimento desigual, combinado e contraditório. A dinâmica do todo não se distribui similarmente pelas partes. As partes, enquanto distintas totalidades também notáveis, consistentes, tanto produzem e reproduzem seus próprios dinamismos como assimilam diferencialmente os dinamismos provenientes da sociedade global, enquanto totalidade mais abrangente. É no nível do desenvolvimento desigual, combinado e contraditório, que se expressam diversidades, localismos, singularidades, particularismos ou identidades. Às vezes, os localismos, provincianismos ou nacionalismos podem exacerbar-se, precisamente devido aos desencontros, às potencialidades e dinâmicas próprias de cada um, cada parte; e também devido às potenciaçôes provenientes da dinâmica da sociedade global, das relações, processos e estruturas que movimentam o todo abrangente. Sob vários aspectos, a ressurgência de nacionalismos, regionalismos, provincianismos, etnicismos, fundamentalismos e identidades são fenômenos que se esclarecem melhor quando vistos nos horizontes dos rearranjos e tensóes provocados pela emergência da sociedade global. À medida em que esta debilita o estado-naçăo, reduz os espaços da soberania nacional, transforma a sociedade nacional em província da global, nessa medida reflorescem identidades pretéritas e presentes, novas e anacrônicas. Também por isto a globalização não significa nunca homogeneização, mas diferenciação em outros níveis, diversidades com outras potencialidades, desigualdades com outras forças. Nesse horizonte, a sociedade global pode ser vista como uma totalidade desde o início problemática, no sentido de complexa e contraditória; atravessada pelo desenvolvimento desigual, combinado e contraditório, que se especifica no âmbito de indivíduos, grupos, classes, tribos, naçốes, sociedades, culturas, religióes, línguas e outras dimensóes singulares ou particulares.

Terceiro, à medida em que se constitui e desenvolve a sociedade global, como emblema de um novo paradigma das ciências sociais, alguns conceitos, categorias e interpretaçóes podem tornar-se obsoletos, exigir reelaboraçōes ou ser articulados com novas noçóes suscitadas pela reflexão sobre a globalização. Já sáo diversas as noçóes que começam a povoar o pensamento global: globalizaçáo, desterritorialização, re-territorialização, miniaturização, cultural mundial, aldeia global, cidade global, shopping center global, disneylândia global, fábrica global, nova divisão internacional do trabalho, redes de articulaçóes intra e intercorporaçóes, alianças estratégicas de corporaçóes, modernidade-mundo, sistema-mundo, economia-mundo, comunicaçáo mundo, publicidade global, espaço europeu, espaço do Pacífico, capitalismo global, moeda global, capital global, terceiromundializaçáo do Primeiro Mundo, exército industrial ativo e de reserva global, planeta terra, sociedade civil mundial, cidadáo do mundo, contrato social mundial, pensamento universal. 
Quarto, nos horizontes abertos pela sociedade global, a história universal deixa de ser uma fantasia, metáfora ou utopia. À medida em que se organiza e movimenta, as histórias das naçōes e nacionalidades inserem-se de forma cada vez mais dinâmica nos movimentos da história universal. As naçóes e as nacionalidades continuam a desenvolver-se com ritmos marcados por suas singularidades, tradiçōes, forças, dinâmicas, historicidades, míticas. Simultaneamente, no entanto, umas e outras são influenciadas pelos andamentos da história universal. Esse o contexto em que se instauram algumas das novas condições da duração, curta, média ou longa, histórica ou mítica. Já não é mais apenas a grande potência, a metrópole imperialista, que incute de modo mais ou menos exclusivo o seu andamento neste ou naquele segmento ou em grande parte do mundo. Desde que se forma e se desenvolve a sociedade global, com a sua economia política, a sua dinâmica sócio-cultural, desde esse momento as histórias nacionais tendem a ser, em alguma medida, subsumidas pela história universal.

Quinto, é no âmbito da sociedade global, com sua economia política, dinâmica sócio-cultural, historicidade complexa e contraditória, que se concretizam as possibilidades do pensamento global. $O$ que era fantasia, metáfora ou utopia, quando o pensamento se propunha pensar o mundo, equacionar a razão universal, imaginar o cosmopolitismo, diagnosticar as contradiçóes universais, mergulhar nas opacidades do real, quando se forma a sociedade global, tudo isso pode adquirir outro significado, novas possibilidades. Nesse sentido é que a emergência da sociedade global permite repensar a dialética da história esboçada por Marx; ou a teoria da racionalização generalizada sugerida por Weber. Talvez se possa dizer que sem Weber e Marx, fundamentalmente mas não exclusivamente, não é possível pensar, em toda a sua abrangência e complexidade, a sociedade global que se forma no limiar do século XXI. Outra vez, no entanto, isto não significa que se torna possível a transferência ou adaptaçáo pura e simples de conceitos, categorias, interpretaçóes. Pode-se afirmar que as obras de Marx e Weber constituem duas matrizes excepcionalmente fecundas para pensar-se configuraçóes e movimentos da sociedade global. Pensar, compreender e explicar essa sociedade tanto em suas singularidades e particularidades como nos horizontes da história universal.

Nessa perspectiva, a modernidade propriamente dita encontra outras possibilidades de desenvolver-se, seja como razăo instrumental, seja como razão crítica. "No fim das contas, é pois sua globalidade simultaneamente estrutural e planetária que define a modernidade do final do século XX como um momento singular. Globalidade social de um pancapitalismo onipresente e de um sistema social fundado na imbricação e 
interconexáo de múltiplos processos que săo eles mesmos, cada vez mais complexos. Globalidade espacial do planeta intercomunicado, do mercado mundial, do tecnocosmo. Essa é a modernidade-mundo. (...) Tal é, pois, a mutaçáo fundamental realizada pela modernidade: com a mundialização da economia, o tecnocosmo, a internacionalizaçáo da vida social, coloca-se em evidência um sistema global, do qual não existiu jamais um equivalente ao longo da história da humanidade. É impossível ocultar a força qualitativa desta mutação em nome da continuidade capitalista. Também seria desarrazoado reduzi-la à sua dimensão técnica. (...) Momento histórico singular, a modernidade mundo impóe a sua singularidade também à reflexão histórica e ao saber históricon (12).

\section{Notas}

1 Immanuel Wallerstein, Unthinking social science (The limits of nineteenth-century paradigms). Cambridge, Polity Press, 1991, p. 246. Citaçâo retirada do cap. 18: Call for a debate about the paradigm, p. 236-256.

2 Martin Albrow \& Elizabeth King (eds.), Globalization, knowpledge and socicty (Readings from Intemational Sociology). Londres, Sage Publications, 1990, p. 155. Citação de One world society, introduçáo de uma das partes da coletânea reunindo textos de diferentes autores.

3 Anthony Giddens, As conseqülnciass da modemidade, trad. de Raul Fiker. Sáo Paulo, Editora Unesp, 1991, p. 69-70.

4 Talcott Parsons, Evolutionary universals in society. New York, American Sociological Review, v. 29, n. 3, 1964; Talcott Parsons, Politics and social structure. New York, The Free Press, 1969, cap. 12: Order and community in the international social system; Harold D. Lasswell, World organization and society, Daniel Lerner e Harold D. Lasswell (eds.), The policy sciences, Stanford, Stanford University Press, 1965, cap. VI; Alex Inkles, The emerging social structure of the world, Princeton, World polities, v. XXVII, n. 4, 1975, p. 467-495; Wilbert E. Moore, Global sociology: the world as a singular system, Chicago, The American Joumal of Sociology, v. LXXI, n. 5, 1966, p. 475-482; Niklas Luhmann, The world society as a social system, International Jowrnal of General Systems, v. 8, 1982, p. 131-138; Robert W. Cox, On thinking abour funure world order, Princeton, World Politics, v. XXVII, n. 2, 1976, p. 175-196; C. E. Black, The dymamics or modermization (A study in comparative history), New York, Harper \& Row Publishers, 1966.

5 Albert Bergesen, The emerging science of the world-system, Intrmational Social Scionce Joumal, v. XXXIV, n. 1, UNESCO, 1982, p. 23-36; ciraçäo das p. 23-24.

6 Martin Albrow, Globalization, knowledge and society, publicado por Martin Albrow e Elizabeth King (eds.), Globalization, knowpledge and socicty (Readings from Intomational sociology), London, Sage Publications, 1990, p. 3-13; citaçăo da p. 9.

7 Immanuel Wallerstein, World-systems analysis, publicado por Anthony Giddens e Jonathan H. Turner (eds.), Social theory today, Cambridge, Polity Press, 1987, p. 309-324; citaçăo da p. 312; consultar também: Immanuel Wallerstein, Untbinking social 
science (The limits of nineteenth-century paradigms), Cambridge, Polity Press, 1991, especialmente parte VI: World-systems analysis as unthinking.

8 Milton Santos, A aceleraçāo contemporânea: tempo mundo e espaço mundo, conferência de abertura do Encontro Internacional $O$ novo mapa do mundo, Departamento de Geografia, Universidade de Sáo Paulo, 1 de set. 1992; citação da p. 4. Do mesmo autor: Les espaces de la globalisation, comunicação apresentada no Seminário organizado por Gemdev. Paris, 4-5 fev. 1993.

9 Mona Abaza e Georg Stauth, Occidental reason, orientalism, islamic fundamentalism: a critique, publicado por Martin Albrow e Elizabeth King, Globalization, knowledge and socicty, citado, p. 209-230; citaçäo da p. 211.

10 Roland Robertson, Globalization (social theory and global culture), London, Sage Publications, 1992, p. 173. Consultar: International Social Science Joumal, n. 117, UNESCO, 1988, n' especial sobre The local-globe nexus; Cliffor Geertz, Sapoir local, savoir global (Les lieux du savoir), trad. de Denise Paulme, Paris, Presses Universitaires de France, 1986.

11 Charles Bright e Michael Geyer, For a unified history of the world in the twentieth century, Radical History Review, n. 39, 1987, p. 69-91; George E. Marcus, Past, present and emergent identities: requirements for ethnographies of late twentieth century modernity worldwide, Anais da 17" Rensiata, Florianópolis, Associação Brasileira de Antropologia, 1990, p. 21-46.

12 Jean Chesneaux, Modernitt-monde (Brave modern world), Paris, Éditions La Découverte, 1989, p. 196, 198 e 199. Consultar também: Serge Latouche, $L$ occidentalisation du monde, Paris, Éditions La Découverte, 1989; Samir Amin, L'cmpire du chaos (La nouvelle mondialisation capitaliste), Paris, Éditions L'Harmattan, 1991.

\section{Resumo}

As ciências sociais estâo sendo desafiadas a pensar a globalização do mundo. No fim do stculo XX, quando se anuncia o XXI, elas se defrontam com os dilemas que se abrem com a globalizaçăo das coisas, gentes e idéias. Há processos e estruturas sociais, económicos, políticos, culturais e outros que apenas começam a ser estudados. Além do que é local, nacional e regional, colocam-se problemas novos e fundamentais com a emergéncia da sociedade global. As fronteiras geográficas e históricas, culturais e civilizatórias parecem modificar-se em direçöes e formas surpreendentes. Individuo, grupo, classe, coletividade e povo sáo colocados diante de outros horizontes. O próprio pensamento cientffico $t$ desafiado a elaborar conceitos e interpretaçóes para dar conta de realidades pouco conhecidas. As teorias da globalizaçăo, que começam a ser esboçadas, revelam o empenho das ciências sociais em explicar o que há de novo no que vai pelo mundo.

\section{Abstract}

Social sciences are now being challenged to think on the world's globalization. At the end of the twentieth century and dawn of the twenty first, they are faced with the dilemas that open up with the globalization of things, people and ideas: There are social, economical, political, cultural and other processes and structures that are just begining to be studied. 
Besides what is local, national and regional, new and fundamental problems appear with the rising global society. The geographic, historical, cultural and civilizatorian limits seem to change in surprising ways and directions. The individual, group, class, colectivity and people are put before other horizons. The scientific thinking itself is called upon to elaborate concepts and interpretations to account for little known realities. The globalization theories that are just being sketched show the efforts of Social Sciences to explain what is new going on in the world.

Octavio Ianni é sociólogo e professor do Departamento de Sociologia do Instituto de Filosofia e Ciências Humanas da Universidade de Campinas. É autor de $A$ sociedade global (Civilização Brasileira, 1994), entre outros livros. 